Article

\title{
Phenolic Profiles, Antioxidant Capacities, and Inhibitory Effects on Digestive Enzymes of Different Kiwifruits
}

\author{
Hong-Yi Li ${ }^{\dagger}$, Qin Yuan ${ }^{\dagger}$, Yu-Ling Yang, Qiao-Hong Han, Jing-Liu He, Li Zhao, Qing Zhang, \\ Shu-Xiang Liu, De-Rong Lin, Ding-Tao Wu *D and Wen Qin * \\ College of Food Science, Sichuan Agricultural University, Ya'an 625014, Sichuan, China; \\ lhongyi45@163.com (H.-Y.L.); 18983426354@163.com (Q.Y.); yangyulingmie@163.com (Y.-L.Y.); \\ hqhlzy@163.com (Q.-H.H.); hjingliu@163.com (J.-L.H.); zhaoli0608@126.com (L.Z.); \\ zhangqing@sicau.edu.cn (Q.Z.); sliu@sicau.edu.cn (S.-X.L.); lindr2018@sicau.edu.cn (D.-R.L.) \\ * Correspondence: DT_Wu@sicau.edu.cn (D.-T.W.); Qinwen@sicau.edu.cn (W.Q.); \\ Tel.: +86-0835-288-3219 (D.-T.W. \& W.Q.); Fax: +86-0835-288-3219 (D.-T.W. \& W.Q.) \\ + These authors contributed equally to this work.
}

Academic Editors: Margarida Castell Escuer and Mariona Camps-Bossacoma

Received: 11 October 2018; Accepted: 9 November 2018; Published: 13 November 2018

check for updates

\begin{abstract}
In order to obtain high-quality kiwifruits with health-promoting characteristics, physicochemical properties, phenolic profiles, antioxidant capacities, and inhibitory effects on digestive enzymes (pancreatic lipase and $\alpha$-glucosidase), of fourteen different types of kiwifruit obtained from China were systematically investigated and compared. Noticeable variations in the fruits' physicochemical properties and phenolic profiles were observed among them. The total phenolic content of Actinidia chinensis cv. Hongshi, A. chinensis cv. Jinshi, and A. chinensis cv. Jinlong were $16.52 \pm 0.26 \mathrm{mg} \mathrm{GAE} / \mathrm{g}$ DW (dry weight), $13.38 \pm 0.20 \mathrm{mg}$ GAE/g DW, and $11.02 \pm 0.05 \mathrm{mg} \mathrm{GAE} / \mathrm{g} \mathrm{DW}$, respectively, which were much higher than those of the other tested kiwifruits. According to high performance liquid chromatography (HPLC) analysis, phenolic compounds, including procyanidin B1, procyanidin B2, (-)-epicatechin, chlorogenic acid, gallic acid, and quercetin-3-rhamnoside, were found to be the major compounds in kiwifruits, while procyanidin B1, procyanidin B2, and chlorogenic acid were the most abundant phenolic compounds. Furthermore, all the tested kiwifruits exerted remarkable antioxidant capacities and inhibitory effects on pancreatic lipase and $\alpha$-glucosidase. Indeed, $A$. chinensis cv. Hongshi, Actinidia chinensis cv. Jinshi, and Actinidia chinensis cv. Jinlong exhibited much better antioxidant capacities and inhibitory effects on digestive enzymes than those of the other tested kiwifruits. Particularly, A. polygama showed the highest inhibitory activity on $\alpha$-glucosidase. Therefore, Actinidia chinensis cv. Hongshi, Actinidia chinensis cv. Jinshi, and Actinidia chinensis cv. Jinlong, as well as A. polygama could be important dietary sources of natural antioxidants and natural inhibitors against pancreatic lipase and $\alpha$-glucosidase, which is helpful for meeting the growing demand for high-quality kiwifruits with health-promoting characteristics in China.
\end{abstract}

Keywords: kiwifruit; phenolic compounds; HPLC analysis; antioxidant capacity; enzyme inhibition

\section{Introduction}

Epidemiological studies have shown that a diet rich in fruits is associated with a lower risk of many diseases, such as cardiovascular diseases, diabetes, and even cancer [1-3]. The health benefits of fruits are partially attributed to the high content of bioactive components, such as phenolics and ascorbic acid [4,5]. Growing evidences indicate that the dietary consumption of phenolic-rich fruits can protect against oxidative damage [6,7]. Moreover, it is increasingly documented that phenolic 
compounds can also affect the digestive enzymes involved in the hydrolysis of dietary carbohydrates and fats [8]. Pancreatic lipase and $\alpha$-glucosidase are key enzymes responsible for the hydrolysis of dietary fats and carbohydrates, respectively [8,9]. The inhibition of pancreatic lipase and $\alpha$-glucosidase by phenolic-rich fruits may offer a natural dietary approach for preventing postprandial hyperglycemia and obesity $[8,10]$. Therefore, the dietary consumption of fruits seems to be a reasonable option for the prevention and treatment of oxidative damage, obesity, and type II diabetes.

Kiwifruit is one of the most popular fruits in the world because of its flavor and health benefits [11,12]. The world production of kiwifruit was around 3,447,604 tons in 2016, accounting for around $0.5 \%$ of the world's total fruit production. Indeed, China is the main producer of kiwifruit, accounting for 1.84 million tons and $53.4 \%$ of worldwide kiwifruit production [13]. In the last three decades, kiwifruit production has grown greatly to around 3.5 times in size. This tendency shows that kiwifruit is becoming more popular, probably due to their health benefits [13]. It is widely believed that the consumption of kiwifruits has a preventive effect against cardiovascular disease and obesity $[1,8]$. Indeed, it is confirmed that kiwifruits have various biological activities [13], such as antioxidant [14], anti-diabetes [8,14], anti-obesity [8,13], anti-proliferative [2], and anti-inflammatory activities [15]. Generally, phenolic compounds and ascorbic acid are considered the main bioactive components in kiwifruit, which are responsible for its various bioactivities $[13,14]$. When compared with orange, apple, peach, pear, banana, pineapple, red grapefruit, and other fruits, kiwifruits exhibit higher content of total phenolic compounds and higher antioxidant capacity [8]. Additionally, one kiwifruit can fulfill $85 \%$ of our daily ascorbic acid requirements [13]. The dietary consumption of kiwifruits makes a substantial contribution to its health-promoting effects. Furthermore, the phenolic compounds and bioactivities of kiwifruits are influenced by species and cultivars [14]. Regarding the genus of kiwifruit, there are more than 70 species in the world [16], and different kiwifruit cultivars have been cultivated during the past several decades, especially in New Zealand, Poland, and Greece. Indeed, different kiwifruit species and many new kiwifruit cultivars have also been widely cultivated and developed in China (Figure 1), respectively [17]. However, there are limited reports on the comparison of phenolic profiles and bioactive properties of different kiwifruit species and newly developed cultivars collected in China.

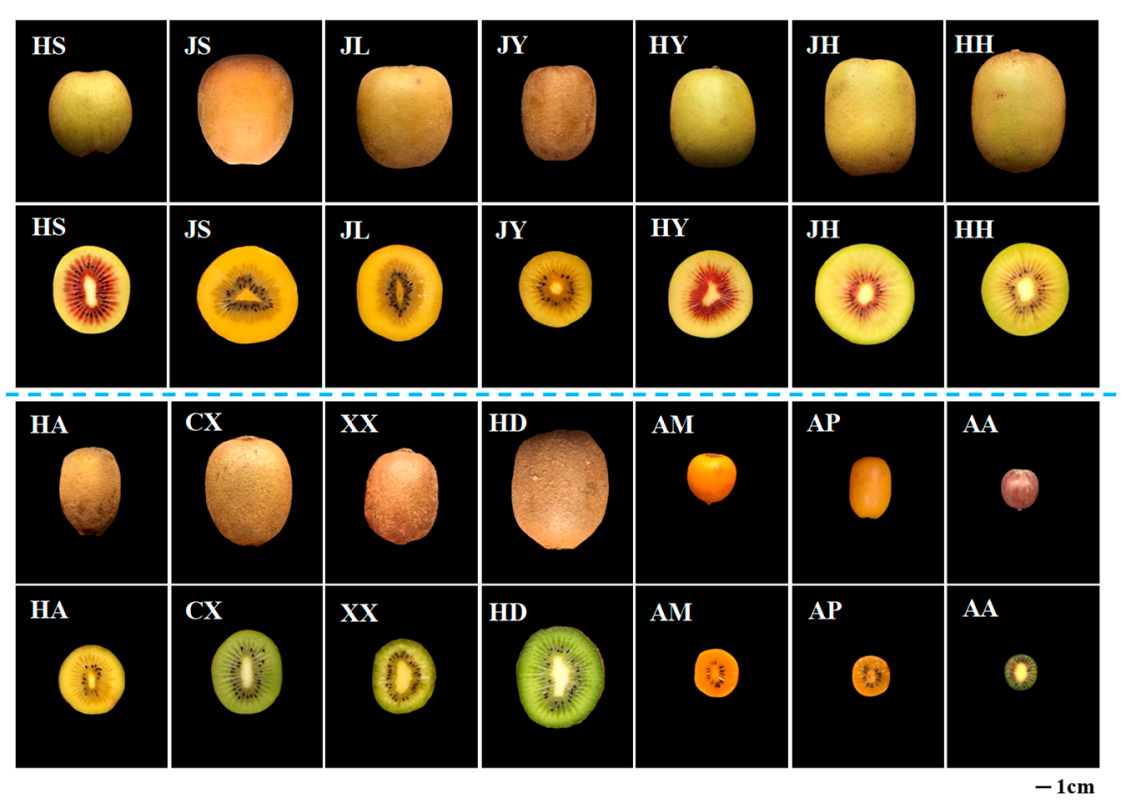

Figure 1. Morphological characteristics of representative kiwifruits collected in China. HS, Actinidia chinensis cv. Hongshi; JS, A. chinensis cv. Jinshi; JL, A. chinensis cv. Jinlong; HY, A. chinensis cv. Hongyang; JH, A. chinensis cv. Jinhong; HH, A chinensis cv. Honghua; HA, A chinensis cv. Hort16A; CX, A. deliciosa cv. Cuixiang; XX, A. deliciosa cv. Xuxiang; HD, A. deliciosa cv. Hayward; AM, A. macrosperma; AP, A. polygama; AA, A. arguta. 
Nowadays, with improvements in quality of life, consumers are attaching increasing importance to health. An increasing number of consumers are not only searching for a kiwifruit cultivar which is sweet and has good flavor, but also health-promoting compounds, such as phenolic compounds [17]. Therefore, it is necessary to evaluate and compare the bioactive components and properties of different kiwifruits, which is helpful for meeting the growing demand for high-quality fruits with health-promoting characteristics in China. However, the biological activities of different kiwifruit species and newly developed cultivars collected in China have seldom been evaluated. Moreover, identification and quantification of phenolic profiles of different kiwifruits are critical starting points for assessing their biological properties [14]. Therefore, in this study, in order to obtain high-quality kiwifruits with health-promoting characteristics, the physicochemical properties, phenolic profiles, antioxidant capacities, and inhibitory effects on digestive enzymes (pancreatic lipase and $\alpha$-glucosidase) of different kiwifruit species and newly developed cultivars collected in China were systematically investigated and compared.

\section{Results and Discussion}

\subsection{Physicochemical Properties of Different Kiwifruits}

The physicochemical properties of different kiwifruits, including the fresh weight per fruit, soluble solids content (SSC), and dry matter content, are shown in Table 1. Results showed that significant $(p<0.05)$ differences in the fresh weight per fruit, dry matter, and SSC were found among the tested kiwifruits. Briefly, the fresh weight per fruit ranged from $7.10 \pm 0.37 \mathrm{~g}$ (A. arguta) to $133.74 \pm 5.66 \mathrm{~g}$ (A. chinensis cv. Jinlong). The fresh weights per fruit of $A$. macrosperma, A. polygama, and A. arguta were much lower than those of $A$. chinensis and A. deliciosa, which is a similar result to previous studies [18]. Generally, the SSC consists of sugar, acid, vitamins, some minerals, and other soluble solid content, which is an important index of fruit taste quality and consumer acceptability $[14,19]$. The SSC ranged from $13.1 \%$ (A. chinensis cv. Jinyan) to $17.6 \%$ (A. chinensis cv. Hongyang), which is in accordance with a previous study [14]. A. chinensis cv. Hongyang, A. chinensis cv. Hongshi, A. chinensis cv. Jinshi, A. chinensis cv. Jinlong, and A. chinensis cv. Jinhong contained much more SSC $(>16.1)$ than those of the other tested kiwifruits. According to some previous studies, the SSC of kiwifruits could be influenced by different environmental conditions and species [20,21]. Moreover, the dry matter of 14 different kiwifruits varied from $13.48 \%$ (A. deliciosa cv. Hayward) to $20.35 \%$ (A. arguta).

Furthermore, the content of ascorbic acid is a preferential factor for the evaluation of the quality of fruits [22]. Kiwifruits may be considered a good source of ascorbic acid. As shown in Table 1, the ascorbic acid content in different kiwifruits varied from $51.32 \pm 0.42$ to $390.68 \pm 4.24 \mathrm{mg} / 100$ g FW (fresh weight). Briefly, the ascorbic acid content of newly developed A. chinensis cv. Hongshi, A. chinensis cv. Jinshi, and A. chinensis cv. Jinlong were $390.68 \pm 4.24 \mathrm{mg} / 100 \mathrm{~g}$ FW, $235.30 \pm 8.27 \mathrm{mg} / 100 \mathrm{~g} \mathrm{FW}$, and $335.06 \pm 10.39 \mathrm{mg} / 100 \mathrm{~g} \mathrm{FW}$, respectively, which were much higher than that of the most commercialized A. deliciosa cv. Hayward (59.32 $\pm 1.89 \mathrm{mg} / 100 \mathrm{~g} \mathrm{FW})[7,17]$. The content of ascorbic acid was not only strongly affected by type of species, but also by different cultivars $[1,14]$. 
Table 1. Fruit weight, soluble solids content (SSC), dry matter, and ascorbic acid of different kiwifruits.

\begin{tabular}{|c|c|c|c|c|c|c|c|c|}
\hline Samples & Codes & Harvest Date & Regions & Flesh Color & Fruit Weight (g) & $\operatorname{SSC}(\%)$ & Dry Matter (\%) & $\begin{array}{l}\text { Ascorbic Acid } \\
\text { (mg/100 g FW) }\end{array}$ \\
\hline \multicolumn{9}{|c|}{ A. chinensis } \\
\hline Hongshi & HS & 28 September 2017 & Mianzhu, Sichuan, China & Green, and red (middle part) & $58.07 \pm 2.17 \mathrm{~g}$ & $16.3 \pm 0.1^{\mathrm{b}}$ & $16.49 \pm 0.18^{\mathrm{e}}$ & $390.68 \pm 4.24^{\mathrm{a}}$ \\
\hline Jinshi & JS & 15 October 2017 & Mianzhu, Sichuan, China & Yellow & $107.19 \pm 1.48^{\mathrm{c}}$ & $16.1 \pm 0.1^{b, c}$ & $16.55 \pm 0.05^{\mathrm{e}}$ & $235.30 \pm 8.27^{\mathrm{c}}$ \\
\hline Jinlong & $\mathrm{JL}$ & 2 November 2017 & Xianyang, Shaanxi, China & Yellow & $118.25 \pm 7.41^{b}$ & $16.1 \pm 0.1^{c}$ & $15.88 \pm 0.10^{\mathrm{f}, \mathrm{g}}$ & $335.06 \pm 10.39^{b}$ \\
\hline Jinyan & $J Y$ & 26 October 2017 & Chengdu, Sichuan, China & Yellow & $88.47 \pm 5.30^{\mathrm{e}}$ & $13.1 \pm 0.1^{\mathrm{i}}$ & $12.45 \pm 0.01^{\mathrm{j}}$ & $97.27 \pm 3.59 \mathrm{~g}$ \\
\hline Hongyang & HY & 28 September 2017 & Cangxi, Sichuan, China & Green, and red (middle part) & $95.57 \pm 10.22^{\mathrm{d}}$ & $17.6 \pm 0.1^{\mathrm{a}}$ & $18.33 \pm 0.09^{b}$ & $107.56 \pm 1.34^{\mathrm{f}}$ \\
\hline Jinhong & $\mathrm{JH}$ & 4 September 2017 & Dayi, Sichuan, China & Green, and red (middle part) & $133.74 \pm 5.66^{\mathrm{a}}$ & $16.1 \pm 0.1^{\mathrm{c}}$ & $16.63 \pm 0.06^{\mathrm{e}}$ & $53.42 \pm 1.78^{\mathrm{j}, \mathrm{k}}$ \\
\hline Honghua & $\mathrm{HH}$ & 8 September 2017 & Pujiang, Sichuan, China & Green, and red (middle part) & $107.80 \pm 7.74^{c}$ & $14.3 \pm 0.1^{\mathrm{f}}$ & $15.75 \pm 0.04^{\mathrm{f}, \mathrm{g}}$ & $61.45 \pm 1.22^{\mathrm{i}}$ \\
\hline Hort16A & HA & 26 October 2017 & Chengdu, Sichuan, China & Yellow & $47.98 \pm 4.49^{\mathrm{h}}$ & $15.8 \pm 0.3^{\mathrm{d}}$ & $15.67 \pm 0.02 \mathrm{~g}$ & $129.10 \pm 3.24 \mathrm{e}$ \\
\hline \multicolumn{9}{|c|}{ A. deliciosa } \\
\hline Cuixing & $C X$ & 27 October 2017 & Xianyang, Shaanxi, China & Green & $78.53 \pm 3.16^{\mathrm{f}}$ & $16.2 \pm 0.1^{b, c}$ & $17.54 \pm 0.05^{\mathrm{c}}$ & $169.54 \pm 2.88^{\mathrm{d}}$ \\
\hline Xuxiang & $x X$ & 26 October 2017 & Chengdu, Sichuan, China & Green & $59.90 \pm 3.53 \mathrm{~g}$ & $13.7 \pm 0.1^{\mathrm{f}, \mathrm{h}}$ & $14.53 \pm 0.09 \mathrm{~h}$ & $84.38 \pm 1.44^{\mathrm{h}}$ \\
\hline Hayward & HD & 8 August 2017 & Xianyang, Shaanxi, China & Green & $113.77 \pm 8.65^{b}$ & $13.6 \pm 0.1^{\mathrm{h}}$ & $13.48 \pm 0.02^{\mathrm{i}}$ & $59.32 \pm 1.89^{i, j}$ \\
\hline A. macrosperma & $\mathrm{AM}$ & 24 August 2017 & Pujiang, Sichuan, China & Orange & $12.79 \pm 0.89^{\mathrm{i}}$ & $13.9 \pm 0.1 \mathrm{~g}, \mathrm{f}$ & $15.97 \pm 0.36^{\mathrm{f}}$ & $61.06 \pm 2.91^{\mathrm{i}}$ \\
\hline A. polygama & $\mathrm{AP}$ & 24 August 2017 & Pujiang, Sichuan, China & Orange & $14.31 \pm 1.25^{\mathrm{i}}$ & $14.0 \pm 0.1^{\mathrm{g}}$ & $17.08 \pm 0.15^{d}$ & $85.94 \pm 0.94^{\mathrm{h}}$ \\
\hline A. arguta & AA & 24 August 2017 & Pujiang, Sichuan, China & Green & $7.10 \pm 0.37^{j}$ & $15.4 \pm 0.1^{\mathrm{e}}$ & $20.35 \pm 0.31^{\mathrm{a}}$ & $51.32 \pm 0.42 \mathrm{k}$ \\
\hline
\end{tabular}

Values represent mean \pm standard deviation. Different letters (a-k) in the same column indicate significant differences at $p<0.05$ determined by ANOVA, followed by Duncan's test. The sample codes were the same as in Figure 1. 


\subsection{Phenolic Profiles of Different Kiwifruits}

Phenolic compounds are considered the main bioactive components in kiwifruits [14]. However, the phenolic compounds of different kiwifruit species and newly developed cultivars collected in China have seldom been evaluated. As shown in Table 2, the total phenolic content (TPC) among the fourteen different kiwifruits differed significantly $(p<0.05)$, ranging from $3.75 \pm 0.09 \mathrm{mg}$ GAE/g DW to $16.52 \pm 0.26 \mathrm{mg} \mathrm{GAE} / \mathrm{g}$ DW. Results showed that the TPC of different kiwifruits was significantly affected by different species and cultivars. Briefly, the total phenolic content of newly developed A. chinensis cv. Hongshi, A. chinensis cv. Jinshi, and A. chinensis cv. Jinlong were $16.52 \pm 0.26 \mathrm{mg}$ GAE/g DW, $13.38 \pm 0.20 \mathrm{mg}$ GAE/g DW, and $11.02 \pm 0.05 \mathrm{mg}$ GAE/g DW, respectively, which were significantly $(p<0.05)$ higher than those of the other tested kiwifruits. However, the lowest level of TPC was found in the most commercialized A. deliciosa cv. Hayward ( $3.75 \pm 0.09 \mathrm{mg}$ GAE/g DW). Similar studies also showed that the total phenolic content in kiwifruits with red flesh (A. chinensis $\mathrm{cv}$. Hongyang) and yellow flesh (A. deliciosa cv. Jinkui) were higher than that of kiwifruits with green flesh (A. deliciosa cv. Hayward) [1]. Generally, the genus and cultivar of kiwifruit, climatic conditions, harvest time, and extraction processes could affect the content of phenolic compounds $[14,23,24]$.

Table 2. Total phenolic content (TPC), ABTS and DPPH radical scavenging capacities, and ferric reducing antioxidant power (FRAP) of different kiwifruits.

\begin{tabular}{ccccc}
\hline Code & $\begin{array}{c}\text { TPC } \\
(\mathbf{m g} \text { GAE/g DW) }\end{array}$ & $\begin{array}{c}\text { ABTS } \\
(\mu \text { mol Trolox/g DW) }\end{array}$ & $\begin{array}{c}\text { DPPH } \\
(\mu \text { mol Trolox/g DW) }\end{array}$ & $\begin{array}{c}\text { FRAP } \\
(\mu \text { mol Trolox/g DW) }\end{array}$ \\
\hline HS & $16.52 \pm 0.26^{\mathrm{a}}$ & $160.36 \pm 6.15^{\mathrm{a}}$ & $87.38 \pm 4.32^{\mathrm{a}}$ & $149.97 \pm 6.98^{\mathrm{a}}$ \\
JS & $13.38 \pm 0.20^{\mathrm{b}}$ & $117.90 \pm 2.09^{\mathrm{b}}$ & $71.60 \pm 4.04^{\mathrm{b}}$ & $142.58 \pm 3.72^{\mathrm{b}}$ \\
JL & $11.02 \pm 0.05^{\mathrm{c}}$ & $90.78 \pm 1.29^{\mathrm{c}}$ & $60.14 \pm 2.07^{\mathrm{c}}$ & $120.04 \pm 1.82^{\mathrm{c}}$ \\
JY & $6.71 \pm 0.12^{\mathrm{e}}$ & $47.92 \pm 1.64^{\mathrm{g}}$ & $26.46 \pm 0.66^{\mathrm{e}}$ & $54.69 \pm 1.48^{\mathrm{d}}$ \\
HY & $6.22 \pm 0.21^{\mathrm{f}}$ & $62.93 \pm 1.31^{\mathrm{e}}$ & $22.97 \pm 0.53^{\mathrm{f}}$ & $52.73 \pm 1.75^{\mathrm{d}}$ \\
JH & $5.29 \pm 0.10^{\mathrm{h}}$ & $38.16 \pm 1.03^{\mathrm{i}}$ & $13.12 \pm 0.07^{\mathrm{h}}$ & $25.42 \pm 0.77^{\mathrm{f}}$ \\
HH & $4.70 \pm 0.10^{\mathrm{i}}$ & $42.68 \pm 1.24^{\mathrm{h}}$ & $13.55 \pm 0.73^{\mathrm{h}}$ & $29.03 \pm 0.47^{\mathrm{f}}$ \\
HA & $6.60 \pm 0.14^{\mathrm{e}}$ & $50.14 \pm 0.24^{\mathrm{g}}$ & $26.88 \pm 0.09^{\mathrm{e}}$ & $53.84 \pm 2.06^{\mathrm{d}}$ \\
CX & $6.06 \pm 0.13^{\mathrm{f}}$ & $55.71 \pm 1.32^{\mathrm{f}}$ & $28.10 \pm 2.01^{\mathrm{e}}$ & $54.11 \pm 0.58^{\mathrm{d}}$ \\
XX & $5.29 \pm 0.10^{\mathrm{h}}$ & $39.52 \pm 0.56^{\mathrm{h}, \mathrm{i}}$ & $19.54 \pm 0.71 \mathrm{~g}$ & $37.75 \pm 1.67^{\mathrm{e}}$ \\
HD & $3.75 \pm 0.09^{\mathrm{j}}$ & $32.95 \pm 0.29^{\mathrm{j}}$ & $15.67 \pm 0.42^{\mathrm{h}}$ & $26.43 \pm 0.97^{\mathrm{f}}$ \\
AM & $8.15 \pm 0.19^{\mathrm{d}}$ & $84.07 \pm 0.61^{\mathrm{d}}$ & $39.69 \pm 1.85^{\mathrm{d}}$ & $54.75 \pm 0.37^{\mathrm{d}}$ \\
AP & $5.57 \pm 0.12^{\mathrm{g}}$ & $64.71 \pm 1.40^{\mathrm{e}}$ & $21.47 \pm 0.17^{\mathrm{f}, \mathrm{g}}$ & $38.18 \pm 0.77^{\mathrm{e}}$ \\
AA & $4.71 \pm 0.18^{\mathrm{i}}$ & $55.81 \pm 0.71^{\mathrm{f}}$ & $14.08 \pm 0.20^{\mathrm{h}}$ & $27.24 \pm 0.41^{\mathrm{f}}$ \\
\hline
\end{tabular}

Values represent mean \pm standard deviation. Different letters $(\mathrm{a}-\mathrm{j})$ in the same column indicate significant differences at $p<0.05$ determined by ANOVA, followed by Duncan's test. The sample codes were the same as in Table 1 .

Furthermore, in order to properly understand the differences between individual phenolic compounds in tested kiwifruits, the HPLC-DAD analysis was performed. Previous studies have shown that flavan-3-ols (such as (-)-epicatechin, (+)-catechin), procyanidin B1, and procyanidin B2), hydroxybenzoic acids (such as gallic acid and protocatechuic acid), hydroxycinnamic acids (such as chlorogenic acid, neochlorogenic acid, and caffeic acid), and flavonols (such as quercetin-3-rhamnoside, quercetin-3-O-glucoside, and rutin) have been identified and found as the major phenolic compounds in kiwifruits $[14,17,21,25]$. Therefore, a total of fifteen commercially available phenolic compounds, including (+)-catechin, (-)-epicatechin, procyanidin B1, procyanidin B2, quercetin, rutin, kaempferol, quercetin-3-O-glucoside, quercetin-3-rhamnoside, chlorogenic acid, neochlorogenic acid, cryptochlorogenic acid, caffeic acid, gallic acid, and protocatechuic acid were selected and investigated in each kiwifruit extract according to previous studies. Figure 2 shows the chromatograms of the mixed standards and representative phenolic profiles of A. chinensis cv. Hongshi. The calibration data (regression equation, linear range, and $\mathrm{R}^{2}$ ) and limits of detection for the fifteen phenolic compounds investigated in kiwifruits are summarized in Table 3. Results showed that the developed HPLC method was suitable for the qualitative and quantitative analysis of phenolic compounds in different kiwifruits. A total of twelve phenolic compounds, including procyanidin B1, procyanidin B2, (-)-epicatechin, (+)-catechin, gallic acid, protocatechuic acid, neochlorogenic acid, chlorogenic acid, caffeic acid, 
rutin, quercetin-3-O-glucoside, and quercetin-3-rhamnoside, were identified in different species and cultivars of kiwifruits based on their HPLC retention time and UV spectra, which is similar with previous studies $[14,17,21,25]$. The content of individual phenolic compounds in different kiwifruits are summarized in Table 4. However, as shown in Table 4, the type and content of phenolic compounds varied significantly by species and cultivars.

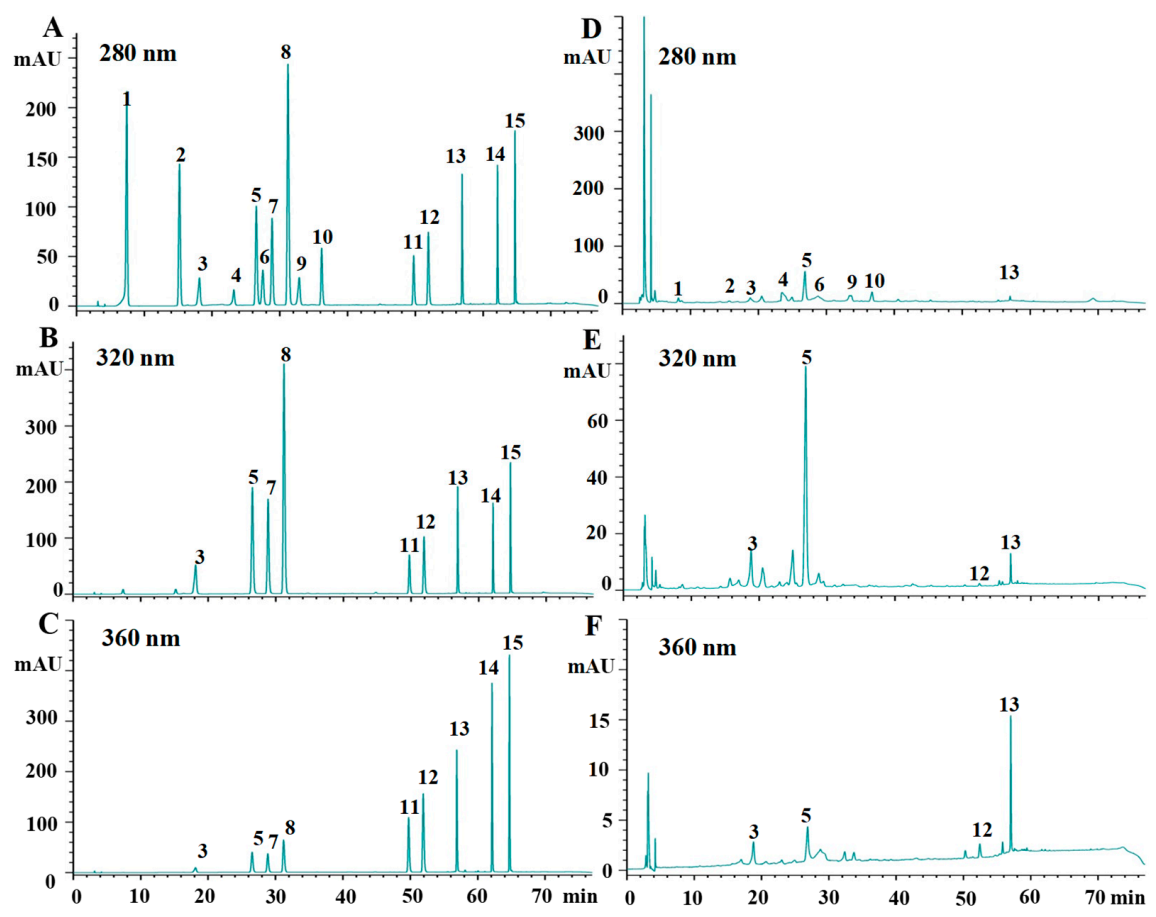

Figure 2. HPLC chromatograms of mixed standards $(\mathbf{A}-\mathbf{C})$ and representative phenolic profiles of A. chinensis cv. Hongshi cultivar (D-F). 1, gallic acid; 2, protocatechuic acid; 3, neochlorogenic acid; 4, procyanidin B1; 5, chlorogenic acid; 6, (+)-catechin; 7, cryptochlorogenic acid; 8, caffeic acid; 9, procyanidin B2; 10, (-)-epicatechin; 11, rutin; 12, quercetin-3-O-glucoside; 13, quercetin-3-rhamnoside; 14, quercetin; 15, kaempferol. Detection was made at $280 \mathrm{~nm}$ for flavan-3-ols and hydroxybenzoic acids, $320 \mathrm{~nm}$ for hydroxycinnamic acids, and $360 \mathrm{~nm}$ for flavonols.

As shown in Table 4, four flavan-3-ols, including two monomeric flavan-3-ols ((-)-epicatechin and (+)-catechin) and two dimeric procyanidins (procyanidin B1 and procyanidin B2), were detected in different species and cultivars of kiwifruits. Results are in accordance with previous studies $[17,25]$. The total flavan-3-ols content in different kiwifruits ranged from $96.07 \mu \mathrm{g} / \mathrm{g}$ DW (A. deliciosa $\mathrm{cv}$. Cuixiang) to $823.61 \mu \mathrm{g} / \mathrm{g}$ DW (A. chinensis cv. Hongshi). The highest content of total flavan-3-ols determined in A. chinensis $\mathrm{cv}$. Hongshi may be attributed to its large part of red flesh, as shown in Figure 1. Briefly, the content of (-)-epicatechin varied significantly among the tested kiwifruits. The highest content of (-)-epicatechin was measured in A. chinensis cv. Hongshi $(162.61 \pm 0.99 \mu \mathrm{g} / \mathrm{g}$ DW). However, (-)-epicatechin was not found in A. chinensis cv. Honghua, A. deliciosa cv. Hayward, and $A$. arguta. As for (+)-catechin, it was only found in A. chinensis cv. Hongshi, A. deliciosa cv. Xuxiang, A. macrosperma, A. polygama, and A. arguta. The highest content of (+)-catechin was measured in A. arguta $(132.08 \pm 1.16 \mu \mathrm{g} / \mathrm{g} \mathrm{DW})$. The procyanidin B1 predominated among the flavan-3-ols. Procyanidin B1 content varied significantly $(p<0.05)$ among different species and cultivars. The highest content of procyanidin B1 was measured in A. chinensis cv. Hongshi $(446.81 \pm 1.51 \mu \mathrm{g} / \mathrm{g}$ DW), which was two times higher than that of the most commercialized A. deliciosa cv. Hayward $(203.68 \pm 4.27 \mu \mathrm{g} / \mathrm{g}$ DW). Similarly to procyanidin B1, procyanidin B2 content also varied greatly among the tested kiwifruits, and the highest content was also measured in A. chinensis cv. Hongshi $(182.11 \pm 1.16 \mu \mathrm{g} / \mathrm{g}$ DW). However, procyanidin B2 was not found in A. chinensis cv. Jinshi, Jinhong, 
and Honghua. Finally, results indicated that (-)-epicatechin and procyanidin B1 were the main flavan-3-ols in kiwifruits, which is in accordance with previous reports $[17,25]$. Results showed that the types and content of flavan-3-ols in kiwifruits were significantly affected by species and cultivars.

Phenolic acids, including two hydroxybenzoic acids (gallic acid and protocatechuic acid) and three hydroxycinnamic acids (chlorogenic acid, neochlorogenic acid, and caffeic acid), were found in different species and cultivars of kiwifruits. The content of total phenolic acids ranged from $26.58 \mu \mathrm{g} / \mathrm{g}$ DW (A. deliciosa cv. Cuixiang) to $315.76 \mu \mathrm{g} / \mathrm{g}$ DW (A. chinensis cv. Hongshi). Briefly, as shown in Table 4, chlorogenic acid, as a caffeoylquinic acid, was not only the main individual hydroxycinnamic acid in different kiwifruits, but also the main individual phenolic compound in different kiwifruits, which is in accordance with previous studies $[17,26]$. The content of chlorogenic acid differed significantly $(p<0.05)$ among the tested kiwifruits, ranging from $7.70 \pm 0.04 \mu \mathrm{g} / \mathrm{g} \mathrm{DW}$ (A. arguta) to $235.75 \pm 5.44 \mu \mathrm{g} / \mathrm{g} \mathrm{DW}$ (A. chinensis cv. Hongshi). Meanwhile, the content of neochlorogenic acid also varied significantly $(p<0.05)$ among the tested kiwifruits. The highest content of neochlorogenic acid was detected in A. chinensis cv. Jinlong (133.72 $\pm 3.98 \mu \mathrm{g} / \mathrm{g}$ DW). However, neochlorogenic acid was not found in $A$. deliciosa cv. Cuixiang, A. deliciosa cv. Xuxiang, A. deliciosa cv. Hayward, A. macrosperma, and A. polygama. Furthermore, caffeic acid was only found in A. macrosperma, A. polygama, and A. arguta, which indicated that the species significantly affected the types of phenolic compounds in kiwifruits. Moreover, gallic acid was the main individual hydroxybenzoic acid found in different kiwifruits, which is in accordance with a previous study [17]. The content of gallic acid varied significantly $(p<0.05)$ among the tested kiwifruits. The top three samples were A. chinensis cv. Jinshi $(53.76 \pm 0.43 \mu \mathrm{g} / \mathrm{g}$ DW) $>$ A. chinensis cv. Jinyan $(49.13 \pm 0.27 \mu \mathrm{g} / \mathrm{g} \mathrm{DW})>A$. chinensis cv. Jinlong $(26.69 \pm 0.45 \mu \mathrm{g} / \mathrm{g} \mathrm{DW})$. However, gallic acid was not detected in A. macrosperma and A. arguta. Additionally, protocatechuic acid was only detected in $A$. chinensis cv. Hongshi, $A$. chinensis cv. Jinshi, and A. polygama, and the highest content was measured in $A$. chinensis cv. Hongshi $(15.76 \pm 0.18 \mu \mathrm{g} / \mathrm{g} \mathrm{DW})$.

Furthermore, three flavonols, including quercetin-3-rhamnoside, quercetin-3-O-glucoside, and rutin were identified in the tested kiwifruits. The content of total flavonols varied greatly among the tested kiwifruits. The main flavonol of the tested kiwifruits was quercetin-3-rhamnoside, which is consistent with previous studies [25,27]. The highest content of quercetin-3-rhamnoside was detected in $A$. chinensis cv. Hongshi $(41.94 \pm 1.44 \mu \mathrm{g} / \mathrm{g} \mathrm{DW})$. However, quercetin-3-rhamnoside was not detected in A. chinensis cv. Jinlong and A. deliciosa cv. Hayward. Moreover, rutin was only found in A. macrosperma, A. polygama, and $A$. arguta. Similarly to rutin, quercetin-3-O-glucoside was also only detected in A. chinensis cv. Hongshi, A. deliciosa cv. Xuxiang, A. polygama, and A. arguta.

Table 3. Calibration data and limits of detection (LOD) for the 15 investigated phenolic compounds in kiwifruit.

\begin{tabular}{ccccc}
\hline Compounds & Regression Equation & Linear Range $(\mu \mathrm{g} / \mathbf{m L})$ & $\mathbf{R}^{\mathbf{2}}$ & LOD $(\mu \mathrm{g} / \mathbf{m L})$ \\
\hline gallic acid & $\mathrm{Y}=54.107 \mathrm{X}-8.928$ & $0.50-10.00$ & 0.9998 & 0.16 \\
protocatechuic acid & $\mathrm{Y}=28.455 \mathrm{X}+0.213$ & $0.78-10.00$ & 1.0000 & 0.26 \\
neochlorogenic acid & $\mathrm{Y}=74.454 \mathrm{X}-4.940$ & $0.22-40.00$ & 1.0000 & 0.07 \\
procyanidin B1 & $\mathrm{Y}=13.806 \mathrm{X}-11.478$ & $2.78-250.00$ & 1.0000 & 0.92 \\
chlorogenic acid & $\mathrm{Y}=71.270 \mathrm{X}-3.391$ & $0.10-40.00$ & 1.0000 & 0.30 \\
(+)-catechin & $\mathrm{Y}=16.756 \mathrm{X}-9.765$ & $2.00-40.00$ & 0.9999 & 0.70 \\
cryptochlorogenic acid & $\mathrm{Y}=59.701 \mathrm{X}+0.326$ & $0.19-1.50$ & 1.0000 & 0.06 \\
caffeic acid & $\mathrm{Y}=102.38 \mathrm{X}-5.749$ & $0.30-12.00$ & 0.9999 & 0.10 \\
procyanidin B2 & $\mathrm{Y}=14.637 \mathrm{X}-2.1539$ & $0.71-50.00$ & 0.9999 & 0.23 \\
(-)-epicatechin & $\mathrm{Y}=20.575 X+0.264$ & $0.50-25.00$ & 1.0000 & 0.16 \\
rutin & $\mathrm{Y}=30.337 \mathrm{X}-6.2411$ & $1.00-10.00$ & 0.9998 & 0.03 \\
quercetin-3-O-glucoside & $\mathrm{Y}=39.956 \mathrm{X}-3.1422$ & $0.44-20.00$ & 0.9998 & 0.12 \\
quercetin-3-rhamnoside & $\mathrm{Y}=34.673 X-8.953$ & $0.75-15.00$ & 0.9993 & 0.25 \\
quercetin & $\mathrm{Y}=67.113 X-22.838$ & $0.80-8.00$ & 0.9992 & 0.26 \\
kaempferol & $\mathrm{Y}=94.982 \mathrm{X}-16.021$ & $0.33-10.00$ & 0.9998 & 0.11 \\
\hline
\end{tabular}

$\mathbf{X}$, concentration $(\mu \mathrm{g} / \mathrm{mL}) ; \mathbf{Y}$, peak area. 
Table 4. Content of phenolic compounds in different kiwifruits.

\begin{tabular}{|c|c|c|c|c|c|c|c|c|c|c|c|c|}
\hline \multirow{2}{*}{ Code } & \multicolumn{4}{|c|}{ Flavan-3-ols ( $\mu \mathrm{g} / \mathrm{g}$ DW) } & \multicolumn{5}{|c|}{ Phenolic Acids ( $\mu \mathrm{g} / \mathrm{g}$ DW) } & \multicolumn{3}{|c|}{ Flavonols ( $\mu \mathrm{g} / \mathrm{g}$ DW) } \\
\hline & PB1 & PB2 & EC & $\mathrm{Ca}$ & GA & PA & CHL & NCHL & CA & QRha & QGlu & Ru \\
\hline HS & $446.81 \pm 1.51^{\mathrm{a}}$ & $182.11 \pm 1.16^{\mathrm{a}}$ & $162.61 \pm 0.99^{a}$ & $32.08 \pm 0.35^{\mathrm{c}}$ & $24.98 \pm 0.19^{\mathrm{d}}$ & $15.76 \pm 0.18^{\mathrm{a}}$ & $235.75 \pm 5.44^{\mathrm{a}}$ & $39.26 \pm 1.41^{c}$ & n.d & $41.94 \pm 1.44^{\mathrm{a}}$ & $6.16 \pm 0.05^{c}$ & n.d \\
\hline JS & $201.69 \pm 2.28^{b}$ & n.d & $60.70 \pm 1.07^{b}$ & n.d & $53.76 \pm 0.43^{\mathrm{a}}$ & $6.55 \pm 0.12^{\mathrm{b}}$ & $78.32 \pm 1.12^{\mathrm{f}}$ & $107.06 \pm 1.74^{b}$ & n.d & $4.59 \pm 0.09 \mathrm{~g}$ & n.d & n.d \\
\hline $\mathrm{JL}$ & $145.68 \pm 3.12^{\mathrm{f}}$ & $20.91 \pm 0.53^{\mathrm{h}}$ & $38.98 \pm 0.94 \mathrm{e}$ & n.d & $26.69 \pm 0.45^{c}$ & n.d & $55.22 \pm 0.48^{\mathrm{h}}$ & $133.72 \pm 3.98^{\mathrm{a}}$ & n.d & n.d & n.d & n.d \\
\hline $\mathrm{JY}$ & $195.99 \pm 4.29^{c}$ & $125.38 \pm 2.00^{\mathrm{C}}$ & $43.41 \pm 0.98^{c}$ & n.d & $49.13 \pm 0.27^{b}$ & n.d & $121.41 \pm 0.92^{\mathrm{c}}$ & $6.29 \pm 0.11^{\mathrm{f}}$ & n.d & $4.73 \pm 0.11 \mathrm{~g}$ & n.d & n.d \\
\hline HY & $132.33 \pm 1.33 \mathrm{~g}$ & $78.62 \pm 1.18^{\mathrm{e}}$ & $45.60 \pm 0.97^{\mathrm{c}}$ & n.d & $14.62 \pm 0.16^{\mathrm{g}}$ & n.d & $97.22 \pm 1.60^{\mathrm{e}}$ & $15.86 \pm 1.04^{\mathrm{e}}$ & n.d & $21.57 \pm 1.08^{c}$ & n.d & n.d \\
\hline $\mathrm{JH}$ & $188.54 \pm 1.73^{\mathrm{d}}$ & n.d & $22.97 \pm 0.15^{\mathrm{h}}$ & n.d & $21.25 \pm 0.35^{\mathrm{f}}$ & n.d & $184.15 \pm 1.97^{\mathrm{b}}$ & $8.27 \pm 0.14^{\mathrm{f}}$ & n.d & $9.16 \pm 0.21^{\mathrm{f}}$ & n.d & n.d \\
\hline $\mathrm{HH}$ & $155.11 \pm 2.32 \mathrm{e}$ & n.d & n.d & n.d & $12.17 \pm 0.25^{\mathrm{h}}$ & n.d & $37.78 \pm 1.19^{\mathrm{i}}$ & $6.53 \pm 0.17^{f}$ & n.d & $7.88 \pm 0.04^{\mathrm{f}}$ & n.d & n.d \\
\hline HA & $203.68 \pm 4.27^{\mathrm{b}}$ & $114.95 \pm 1.84^{\mathrm{d}}$ & $60.56 \pm 1.77^{\mathrm{b}}$ & n.d & $22.68 \pm 0.30^{\mathrm{e}}$ & n.d & $103.65 \pm 1.47^{\mathrm{d}}$ & $17.78 \pm 1.53 \mathrm{~d}, \mathrm{e}$ & n.d & n.d & n.d & n.d \\
\hline$C X$ & $64.60 \pm 1.33^{\mathrm{k}}$ & $17.88 \pm 0.66^{\mathrm{h}}$ & $13.60 \pm 0.30^{\mathrm{i}}$ & n.d & $5.64 \pm 0.13^{k}$ & n.d & $20.94 \pm 0.61^{\mathrm{k}}$ & n.d & n.d & $16.19 \pm 0.53^{\mathrm{e}}$ & n.d & n.d \\
\hline$x x$ & $118.58 \pm 1.72^{\mathrm{h}}$ & $146.28 \pm 2.65^{b}$ & $27.96 \pm 0.63 \mathrm{~g}$ & $14.71 \pm 0.59^{\mathrm{d}}$ & $9.12 \pm 0.08^{\mathrm{j}}$ & n.d & $75.25 \pm 2.52^{\mathrm{f}}$ & n.d & n.d & $32.25 \pm 0.60^{\mathrm{b}}$ & $5.10 \pm 0.12^{c}$ & n.d \\
\hline $\mathrm{HD}$ & $91.03 \pm 1.44^{j}$ & $45.54 \pm 0.87 \mathrm{~g}$ & n.d & n.d & $9.74 \pm 0.13^{\mathrm{i}}$ & n.d & $60.77 \pm 0.49 \mathrm{~g}$ & n.d & n.d & $8.55 \pm 0.17^{\mathrm{f}}$ & n.d & n.d \\
\hline $\mathrm{AM}$ & $107.98 \pm 1.53^{\mathrm{i}}$ & $112.74 \pm 2.19^{\mathrm{d}}$ & $31.48 \pm 1.60^{\mathrm{f}}$ & $28.72 \pm 1.43^{c}$ & n.d & n.d & $27.12 \pm 1.07^{j}$ & n.d & $40.97 \pm 1.15^{a}$ & $8.69 \pm 0.15^{\mathrm{f}}$ & n.d & $17.58 \pm 0.58^{b}$ \\
\hline $\mathrm{AP}$ & n.d & $81.42 \pm 0.98^{\mathrm{e}}$ & $26.12 \pm 0.63 \mathrm{~g}$ & $43.30 \pm 2.47^{\mathrm{b}}$ & $9.90 \pm 0.09^{\mathrm{i}}$ & $12.19 \pm 0.24^{\mathrm{c}}$ & $63.50 \pm 0.89 \mathrm{~g}$ & n.d & $2.69 \pm 0.03^{c}$ & $16.43 \pm 0.41^{\mathrm{d}, \mathrm{e}}$ & $108.60 \pm 0.92 \mathrm{a}$ & $48.23 \pm 0.38^{a}$ \\
\hline AA & $58.72 \pm 0.74^{1}$ & $65.17 \pm 0.45^{f}$ & n.d & $132.08 \pm 1.16^{\mathrm{a}}$ & n.d & n.d & $7.70 \pm 0.04^{1}$ & $21.14 \pm 1.11^{\mathrm{d}}$ & $22.56 \pm 0.90^{b}$ & $17.63 \pm 0.59 \mathrm{~d}$ & $11.02 \pm 0.20^{\mathrm{b}}$ & $8.27 \pm 0.08^{c}$ \\
\hline
\end{tabular}

PB1, procyanidin B1; PB2, procyanidin B2; EC, (-)-epicatechin; Ca, (+)-catechin; GA, gallic acid; PA, protocatechuic acid; CHL, chlorogenic acid; NCHL, neochlorogenic acid; CA, caffeic acid; QRha, Quercetin-3-rhamnoside; QGlu, quercetin-3-O-glucoside; Ru, rutin; n.d, not detected; each value represents the mean \pm standard deviation. Different letters in the same column indicate significant differences at $p<0.05$ determined by ANOVA, followed by Duncan's test. The sample codes are the same as in Table 1. 


\subsection{Antioxidant Capacities of Different Kiwifruits}

The contribution of kiwifruits to health improvement has been partly attributed to their antioxidant capacity [13]. Generally, the antioxidant capacity of fruits is affected by different mechanisms of action of their antioxidant constituents [8]. Therefore, the antioxidant capacity was evaluated by different methods. Table 2 also summarized the antioxidant capacities of different kiwifruits. Significant differences $(p<0.05)$ were found in the tested kiwifruits. Briefly, the antioxidant capacities ranged from $32.95 \pm 0.29 \mu \mathrm{mol}$ Trolox $/ \mathrm{g}$ DW (A. deliciosa cv. Hayward) to $160.36 \pm 6.15 \mu \mathrm{mol}$ Trolox/g DW (A. chinensis cv. Hongshi) in ABTS assay, from $13.12 \pm 0.07 \mu \mathrm{mol}$ Trolox/g DW (A. chinensis cv. Jinhong) to $87.38 \pm 4.32 \mu \mathrm{mol}$ Trolox/g DW (A. chinensis cv. Hongshi) in DPPH assay, and from $27.24 \pm 0.41 \mu \mathrm{mol}$ Trolox/g DW (A. chinensis cv. Jinhong) to $149.97 \pm 6.98 \mu \mathrm{mol}$ Trolox/g DW (A. chinensis cv. Hongshi) in FRAP assay, respectively. These results are similar with previous studies $[24,28]$. A chinensis cv. Hongshi showed the highest antioxidant capacities, followed by $A$. chinensis $\mathrm{cv}$. Jinshi and A. chinensis cv. Jinlong, while A. deliciosa cv. Hayward showed the lowest antioxidant capacities, regardless of assay methods. The differences in antioxidant capacity of the tested kiwifruits could be preliminarily attributed to the different content of phenolic compounds and ascorbic acid. As shown in Table 2, the antioxidant capacities of the tested kiwifruits evaluated by ABTS assay, DPPH assay, and FRAP assay were positively correlated with the TPC, respectively. Generally, phenolic compounds and ascorbic acid play important roles in fruits' antioxidant capacities [14]. Previous studies have shown that both total polyphenols and ascorbic acid are major contributors to the total antioxidant capacity in kiwifruits [28]. In particular, it was reported that chlorogenic acid showed a better correlation with antioxidant activity (DPPH, ABTS, and FRAP) [29]. Thus, it seems likely that the high content of chlorogenic acid could be one of the major contributors to the antioxidant capacities of kiwifruits. Results suggested that A. chinensis cv. Hongshi, A. chinensis cv. Jinshi, and A. chinensis cv. Jinlong could be potential resources of antioxidants for the production of health-benefiting products.

\subsection{Inhibitory Effects on Digestive Enzymes of Different Kiwifruits}

Pancreatic lipase is the most important enzymes responsible for triglyceride digestion. Consequently, the suppression and delay of triglyceride digestion and absorption through inhibition of lipase is a key approach to the control of hyperlipidaemia and obesity [10]. Previous studies have shown that the consumption of kiwifruit plays a significant role in the levels of plasmatic lipids [13], and that kiwifruit extracts exhibit a strong inhibitory effect on pancreatic lipase [8]. However, the inhibitory effects on lipase of different species and cultivars of kiwifruits collected in China have seldom been investigated and compared. As shown in Figure 3A, significant differences $(p<0.05)$ were found among the tested kiwifruits in the inhibitory activities toward pancreatic lipase. The $\mathrm{IC}_{50}$ values of inhibitory effects on pancreatic lipase varied from $3.12 \pm 0.09 \mathrm{mg} / \mathrm{mL}$ to $7.44 \pm 0.11 \mathrm{mg} / \mathrm{mL}$ among the tested kiwifruits. The difference in $\mathrm{IC}_{50}$ values may have resulted from the different levels of TPC in kiwifruits, which suggests that the inhibitory effects on pancreatic lipase were associated with the high content of phenolic compounds [9]. Among the tested kiwifruits, A. chinensis $\mathrm{cv}$. Hongshi showed the highest pancreatic lipase inhibitory activity, whereas the lowest activity was measured in A. macrosperma. In addition, A. chinensis and A. deliciosa showed more potent inhibitory effects on pancreatic lipase than other species (A. macrosperma, A. polygama, and $A$. arguta). Furthermore, the inhibitory effects on pancreatic lipase of the tested kiwifruits (except for $A$. macrosperma) still presented much lower $\mathrm{IC}_{50}$ values when compared with the commercial orlistat drug $\left(\mathrm{IC}_{50}=6.34 \mathrm{mg} / \mathrm{mL}\right)$. Previous studies have reported that proanthocyanidins are effective lipase inhibitors in grape seed extract and strawberry extract [30,31]. In addition, previous studies have shown that quercetin and its derivatives exert an inhibition effect on pancreatic lipase [32,33]. Therefore, it seems likely that proanthocyanidins (procyanidin B1 and procyanidin B2) and quercetin derivatives (quercetin-3-rhamnoside and quercetin-3-O-glucoside) present in kiwifruits could be the major contributors toward the pancreatic lipase inhibition effects of kiwifruits due to their high content. 

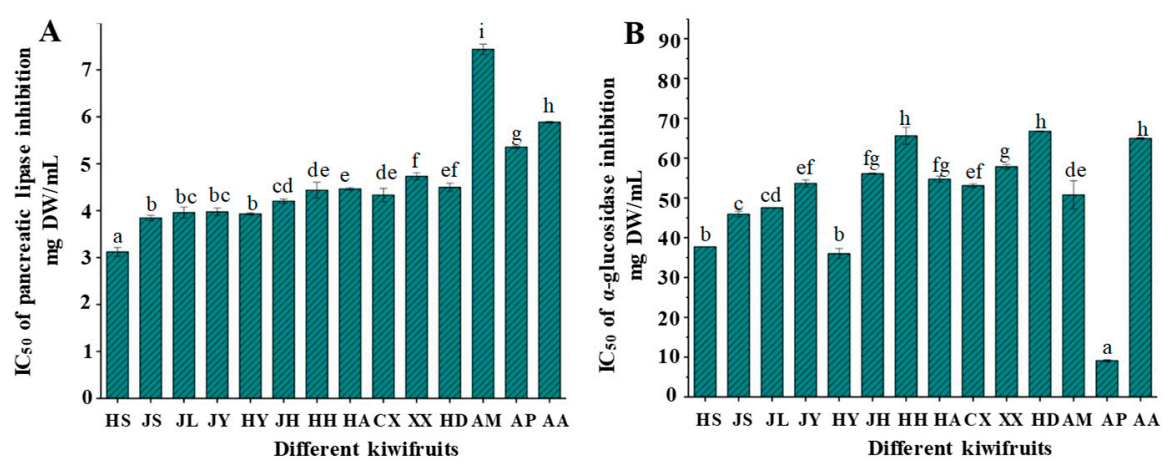

Figure 3. Inhibitory activities on pancreatic lipase (A) and $\alpha$-glucosidase (B) of different kiwifruits. All experiments were conducted in triplicate. Values represent mean \pm standard deviation, and the error bars are standard deviations. Different letters $(a-i)$ in the same column indicate significant differences at $p<0.05$ determined by ANOVA, followed by Duncan's test. The sample codes are the same as in Table 1.

$\alpha$-Glucosidase is a key enzyme responsible for the breakdown of oligosaccharides and disaccharides into monosaccharides suitable for absorption. Therefore, the inhibition of $\alpha$-glucosidase is one of the main strategies to counteract metabolic alterations related to hyperglycaemia and type II diabetes [34]. Previous studies have shown that the kiwifruit extract exhibits a strong inhibitory effect on $\alpha$-glucosidase $[8,14]$. However, different kiwifruits' inhibitory effects on $\alpha$-glucosidase have seldom been investigated. As shown in Figure 3B, significant differences $(p<0.05)$ were found among the tested kiwifruits in the inhibitory activities toward $\alpha$-glucosidase. There was a wide range of $\alpha$-glucosidase inhibition, with the $\mathrm{IC}_{50}$ values ranging from $9.11 \pm 0.24 \mathrm{mg} / \mathrm{mL}$ to $66.73 \pm 0.09 \mathrm{mg} / \mathrm{mL}$. Particularly, A. polygama showed the highest inhibitory activity on $\alpha$-glucosidase, which might be attributed to the high content of quercetin-3-O-glucoside. A previous study showed that the flavonols, especially quercetin-3-O-glucoside, were found to possess high inhibition activity on $\alpha$-glucosidase [9]. Moreover, previous studies have also indicated that chlorogenic acid and its structural isomer are major contributors to the inhibitory activities on $\alpha$-glucosidase [32,35]. The high content of chlorogenic acid and neochlorogenic acid in kiwifruits may explain the $\alpha$-glucosidase inhibitory effect of kiwifruits. Caffeic acid and catechin might also play important roles in $\alpha$-glucosidase inhibition effects [29,32,35]. The order of the most potent $\alpha$-glucosidase inhibitors was as follows: A. polygama $>$ A. chinensis $\mathrm{cv}$. Hongshi $>A$. chinensis cv. Jinshi $>$ A. chinensis cv. Jinlong. Furthermore, compared with the positive inhibitor (acarbose standard, $\mathrm{IC}_{50}=4.63 \mathrm{mg} / \mathrm{mL}$ ), the tested kiwifruits exerted a moderate inhibitory effect towards $\alpha$-glucosidase. However, kiwifruits exhibited stronger antidiabetic activity than orange, mandarine, apple, banana, pineapple, plum, pear, pomelo, and red grapefruit [8].

\section{Materials and Methods}

\subsection{Samples and Chemicals}

Fourteen different kiwifruits, including eight different cultivars of Actinidia chinensis, and three different cultivars of $A$. deliciosa, A. macrosperma, A. polygama, and A. arguta, respectively, were manually collected in different orchards from Sichuan and Shaanxi Province, China. All of the kiwifruit samples were harvested at their commercial maturity (soluble solid content ranging from $6.5 \%$ to $7.5 \%$ ), and then they were ripened at room temperature $\left(20-25^{\circ} \mathrm{C}\right)$ to reach an average firmness of $0.5-1.0 \mathrm{~kg} / \mathrm{cm}^{2}$. The relevant sample information is shown in Table 1 . For each sample, approximately $5 \mathrm{~kg}$ of kiwifruits were collected. The whole kiwifruits were washed with distilled water, and divided into two groups. The fresh kiwifruits were used to measure the soluble solids content, dry matter, and ascorbic acid content (first group). The second group was frozen and freeze-dried. Subsequently, the samples were ground to pass through a 60 -mesh sieve, and stored at $-20^{\circ} \mathrm{C}$ for further analysis. 
Ascorbic acid, (+)-catechin, (-)-epicatechin, procyanidin B1, procyanidin B2, quercetin, rutin, kaempferol, quercetin-3-O-glucoside, quercetin-3-rhamnoside, chlorogenic acid, neochlorogenic acid, cryptochlorogenic acid, caffeic acid, gallic acid, protocatechuic acid, 6-hydroxy-2,5,7,8-tetramethyl chroman-2-carboxylic acid (Trolox), pancreatic lipase, $\alpha$-glucosidase, $p$-nitrophenyl- $\alpha$-D-glucopyranoside (PNPG), $p$-nitrophenyl acetate, 2,2-diphenyl-1-picrylhydrazyl (DPPH), 2,2'-azino-bis (3-ethylenzthiazoline-6-sulphonic acid) (ABTS), 2,4,6-tris-2-pyridyl-s-triazine (TPTZ), and the Folin-Ciocalteu reagent were purchased from Sigma-Aldrich (St. Louis, MO, USA). All other reagents and chemicals used were of analytical grade.

\subsection{Determination of Dry Matter, Soluble Solids Content (SSC), and Ascorbic Acid}

The dry matter was determined by drying slices $(2 \mathrm{~mm})$ from the middle of the kiwifruit pulp at $105{ }^{\circ} \mathrm{C}$ to achieve constantly weight. Furthermore, the pulp of kiwifruit was homogenized in a grinder (Guangming Medical Instrument Co., Ltd, Beijing, China), and the supernatant was collected for analysis of SSC. The SSC was directly measured in the obtained supernatant using a digital refractometer (PAL-1, Atago, Japan). In addition, the content of ascorbic acid was measured according to a previously reported method with minor modifications [36]. Briefly, $3.0 \mathrm{~g}$ of fresh samples were homogenized in $50 \mathrm{~mL}$ of trichloroacetic acid (TCA, $5 \%, w / v)$ pre-cooled on ice, and centrifuged at $5000 \times \mathrm{g}$ for $10 \mathrm{~min}$ at $4{ }^{\circ} \mathrm{C}$. Then, $1 \mathrm{~mL}$ of the supernatant, $1 \mathrm{~mL}$ of $5 \% \mathrm{TCA}, 1 \mathrm{~mL}$ of absolute ethanol, $0.5 \mathrm{~mL}$ of $0.4 \%$ phosphoric acid-ethanol $(v / v), 1 \mathrm{~mL}$ of 1,10 -phenanthroline $(0.5 \%, w / v)$, and $0.5 \mathrm{~mL}$ of ferric trichloride $(0.03 \%, w / v)$ were added sequentially, and incubated at $30^{\circ} \mathrm{C}$ for $60 \mathrm{~min}$ in dark. The absorbance was determined at $534 \mathrm{~nm}$ using a Varioskan Flash Multimode Reader (ThermoFisher, Waltham, MA, USA). A standard curve of ascorbic acid was used for calibration.

\subsection{Extraction of Phenolic Compounds}

The extraction of lyophilized kiwifruits was performed according to a previously reported method with minor modifications [37]. Briefly, $1.0 \mathrm{~g}$ of lyophilized kiwifruit powder was mixed with 30 $\mathrm{mL}$ of $70 \%$ acidified methanol $(0.1 \% \mathrm{HCl}, v / v)$. Then, the mixture was extracted with ultrasound (Kangshijie ultrasound Co., Ltd, Dongguan, Guangzhou, China) $(50 \mathrm{kHz}, 480 \mathrm{~W})$ for $60 \mathrm{~min}$ at room temperature followed by centrifugation (Beckman Coulter, Fullerton, CA, USA) at $6000 \times g$ for $20 \mathrm{~min}$ to collect supernatant, and the extraction was repeated twice under the same extraction conditions. The combined supernatants were evaporated to dryness under a vacuum at $45^{\circ} \mathrm{C}$. The dried residue was then dissolved into $70 \%$ of methanol and stored at $-20^{\circ} \mathrm{C}$ in dark for the further determination of total phenolics, individual phenolic compounds, antioxidant capacities, and inhibitory effects on digestive enzymes. The extract was filtered through a $0.22 \mu \mathrm{m}$ organic membrane prior to analysis using high performance liquid chromatography (HPLC) (Agilent Technologies, Santa Clara, CA, USA).

\subsection{Determination of Total Phenolic Content}

The total phenolic content (TPC) of kiwifruit extract was measured by the Folin-Ciocalteu assay as described previously with minor modifications [37]. Briefly, $100 \mu \mathrm{L}$ of each kiwifruit extract or gallic acid standard solution was mixed with $500 \mu \mathrm{L}$ of Folin-Ciocalteu reagent. Subsequently, $500 \mu \mathrm{L}$ of sodium carbonate solution $(20 \%, w / v)$ was added. After incubation at room temperature for $30 \mathrm{~min}$, the absorbance was measured at $760 \mathrm{~nm}$ using a Varioskan Flash Multimode Reader (ThermoFisher, Waltham, MA, USA). The TPC was expressed as milligram gallic acid equivalent per gram of kiwifruit dry weight (mg GAE/g DW).

\subsection{HPLC Analysis of Individual Phenolic Compounds}

Individual phenolic compounds of kiwifruit extract were evaluated by an Agilent 1260 series LC system (Agilent Technologies, Santa Clara, CA, USA) equipped with a diode-array detector (DAD). Chromatographic separations were conducted at $25^{\circ} \mathrm{C}$ on a ZORBAX Eclipase XDB-C18 column $(250 \mathrm{~mm} \times 4.6 \mathrm{~mm}, 5 \mu \mathrm{m})$. The chromatographic separation was achieved by gradient 
elution with $0.5 \%(v / v)$ acetic acid solution (A) and acetonitrile (B) according to a previous study, with minor modifications [17]. Briefly, samples were eluted as follows: $0 \mathrm{~min}, 5 \% \mathrm{~B} ; 5 \mathrm{~min}$, $5 \% \mathrm{~B} ; 50 \mathrm{~min}, 5-20 \% \mathrm{~B} ; 70 \mathrm{~min}, 20-70 \% \mathrm{~B} ; 72 \mathrm{~min}, 70-5 \% \mathrm{~B}$; and $72-77 \mathrm{~min}, 5 \% \mathrm{~B}$. The flow rate was $0.8 \mathrm{~mL} / \mathrm{min}$, and the injection volume was $20 \mu \mathrm{L}$ for all samples. Detection was made at $280 \mathrm{~nm}$ for flavan-3-ols and hydroxybenzoic acids, $320 \mathrm{~nm}$ for hydroxycinnamic acids, and $360 \mathrm{~nm}$ for flavonols, respectively. Identification of individual phenolic compounds of kiwifruits was carried out by comparing retention times and absorption spectra of commercial standards, and spiking of external reference standards, as well as comparing the information of the same type of samples previously reported $[14,17,38]$. The identified compounds were quantified by an external calibration method using calibration curves. Fifteen standards, including 4 flavan-3-ols $((+)$-catechin, (-)-epicatechin, procyanidin B1, and procyanidin B2), 5 flavonols (quercetin, rutin, kaempferol, quercetin-3-O-glucoside, and quercetin-3-rhamnoside), and 6 phenolic acids (chlorogenic acid, neochlorogenic acid, cryptochlorogenic acid, caffeic acid, gallic acid, and protocatechuic acid) were used for the qualitative and quantitative analysis of individual phenolic compounds in the kiwifruit extract. The content of individual phenolic compounds was expressed as microgram per gram dry weight $(\mu \mathrm{g} / \mathrm{g} \mathrm{DW})$.

\subsection{Determination of Antioxidant Capacities of Kiwifruit Extract}

\subsubsection{ABTS Radical Cation Scavenging Capacity}

The ABTS radical cation scavenging capacity of kiwifruit extract was evaluated according to a previously reported method with minor modifications [37]. Briefly, the ABTS radical cation solution was generated by the interaction of $7 \mathrm{mM}$ ABTS solution and $2.45 \mathrm{mM}$ aqueous potassium persulfate at room temperature for at least $16 \mathrm{~h}$ in the dark. The ABTS radical cation solution was diluted with phosphate buffer $(0.2 \mathrm{M}, \mathrm{pH} 7.4)$ to an absorbance of $0.750 \pm 0.02$ at $734 \mathrm{~nm}$. Then, $200 \mu \mathrm{L}$ of ABTS radical cation working solution was mixed with $20 \mu \mathrm{L}$ of each kiwifruit extract at five different concentrations or phosphate buffer as a negative control in a 96-well microplate to react at $30^{\circ} \mathrm{C}$ for $20 \mathrm{~min}$. The absorbance at $734 \mathrm{~nm}$ was measured. Trolox was used as the standard, and the ABTS radical cation scavenging capacity was expressed as $\mu \mathrm{mol}$ of Trolox equivalent per gram of kiwifruit dry weight ( $\mu \mathrm{mol}$ Trolox/g DW), and the IC50 value of ABTS radical cation scavenging was expressed as $\mathrm{mg}$ of kiwifruit dry weight $/ \mathrm{mL}(\mathrm{mg} / \mathrm{mL})$.

\subsubsection{DPPH Radical Scavenging Capacity}

The DPPH radical scavenging capacity was measured according to a previously reported method with slight modifications [37]. Briefly, $25 \mu \mathrm{L}$ of each kiwifruit extract at five different concentrations or methanol as a negative control was added to $200 \mu \mathrm{L}$ of DPPH solution $(0.35 \mathrm{mM})$ in a 96-well microplate. The mixed solution was shaken and incubated at room temperature for $30 \mathrm{~min}$. Finally, the absorbance was measured at $517 \mathrm{~nm}$ with a blank contain-only DPPH solution and methanol. Trolox was used as the standard, and the DPPH radical scavenging capacity was expressed as $\mu \mathrm{mol}$ of Trolox equivalent per gram of kiwifruit dry weight ( $\mu \mathrm{mol}$ Trolox/g DW). The $\mathrm{IC}_{50}$ value of DPPH radical scavenging capacity was expressed as $\mathrm{mg}$ of kiwifruit dry weight $/ \mathrm{mL}(\mathrm{mg} / \mathrm{mL})$.

\subsubsection{Ferric-Reducing Antioxidant Power (FRAP)}

The FRAP assay was conducted according to a previously reported method with minor modifications [39]. Briefly, the FRAP working solution contained $300 \mathrm{mM}$ acetate buffer ( $\mathrm{pH} 3.6$ ), $10 \mathrm{mM}$ TPTZ solution in $40 \mathrm{mM} \mathrm{HCl}$, and $20 \mathrm{mM} \mathrm{FeCl}_{3}$ solution at a ratio of 10:1:1, and was freshly prepared. The working solution was warmed at $30{ }^{\circ} \mathrm{C}$ before usage. Then, $100 \mu \mathrm{L}$ of each kiwifruit extract was mixed with $3 \mathrm{~mL}$ of FRAP solution and incubated at $37^{\circ} \mathrm{C}$ for $4 \mathrm{~min}$. Finally, the absorbance was measured at $593 \mathrm{~nm}$. Trolox was used as the standard, and the FRAP was expressed as $\mu \mathrm{mol}$ of Trolox equivalent per gram of kiwifruit dry weight ( $\mu \mathrm{mol}$ Trolox/g DW). 


\subsection{Pancreatic Lipase and $\alpha$-Glucosidase Inhibition of Kiwifruit Extract}

The inhibition of pancreatic lipase activity was determined according to a previously reported method with modifications [8]. In brief, the $p$-nitrophenyl acetate $(10 \mathrm{mM}$, dissolved in DMSO) stock solution was diluted with distilled water to reach a final concentration of $2 \mathrm{mM}$. $100 \mu \mathrm{L}$ of each kiwifruit extract at five different concentrations, $200 \mu \mathrm{L}$ of Tris buffer ( $50 \mathrm{mM}, \mathrm{pH} 7.4)$, and $100 \mu \mathrm{L}$ of lipase solution $\left(5 \mathrm{mg} / \mathrm{mL}\right.$, dissolved in $50 \mathrm{mM} \mathrm{pH} 7.4$ Tris buffer) were mixed and incubated at $37^{\circ} \mathrm{C}$ for $10 \mathrm{~min}$. Then, $100 \mu \mathrm{L}$ of p-nitrophenyl acetate solution $(2 \mathrm{mM})$ was added and incubated at $37^{\circ} \mathrm{C}$ for $15 \mathrm{~min}$. Finally, the absorbance was measured at $410 \mathrm{~nm}$. The commercial capsule of orlistat was used as a positive control. The results were expressed as inhibition (\%) of pancreatic lipase activity according to the following equation below. The pancreatic lipase inhibitory effect was measured at five different concentrations, and a logarithmic regression curve was established to calculate $\mathrm{IC}_{50}$ values (mg of kiwifruit dry weight/mL):

$$
\text { Pancreatic lipase inhibition } \%=\left[1-\frac{\mathrm{A}_{\text {sample }}-\mathrm{A}_{\text {blank }}}{\mathrm{A}_{\text {control }}-\mathrm{A}_{\text {solvent blank }}}\right] \times 100 \%
$$

where $\mathrm{A}_{\text {sample }}$ is the absorbance of the mixture of kiwifruit extract, Tris solution, pancreatic lipase solution, and $p$-nitrophenyl acetate solution; $A_{b l a n k}$ is the absorbance of the mixture of kiwifruit extract, Tris solution, and pancreatic lipase solution; $A_{\text {control }}$ is the absorbance of the mixture of methanol, Tris solution, pancreatic lipase solution, and $p$-nitrophenyl acetate solution; and $\mathrm{A}_{\text {solvent blank }}$ is the absorbance of Tris solution.

The $\alpha$-glucosidase inhibitory effect was determined according to a previously reported method with some modifications [8]. Briefly, $100 \mu \mathrm{L}$ of kiwifruit extract at five different concentrations was mixed with $100 \mu \mathrm{L}$ of $\alpha$-glucosidase $(0.5 \mathrm{U} / \mathrm{mL}$, dissolved in $0.1 \mathrm{M} \mathrm{pH} 6.8$ phosphate buffer), and incubated at $37^{\circ} \mathrm{C}$ for $10 \mathrm{~min}$. Then, $25 \mu \mathrm{L}$ of PNPG solution $(4 \mathrm{mM}$, dissolved in $0.1 \mathrm{M} \mathrm{pH}$ 6.8 phosphate buffer) was added to initiate the reaction at $37^{\circ} \mathrm{C}$ for $20 \mathrm{~min}$. The absorbance was measured at $405 \mathrm{~nm}$. The $\alpha$-glucosidase inhibitor (acarbose standard) was used as a positive control. The results were expressed as inhibition (\%) of $\alpha$-glucosidase activity, according to the following equation below. $\alpha$-Glucosidase inhibitory effect was measured at five different concentrations, and a logarithmic regression curve was established to calculate $\mathrm{IC}_{50}$ values (mg of kiwifruit dry weight $/ \mathrm{mL}$ ):

$$
\alpha \text {-Glucosidase inhibition } \%=\left[1-\frac{\mathrm{A}_{\text {sample }}-\mathrm{A}_{\text {blank }}}{\mathrm{A}_{\text {control }}-\mathrm{A}_{\text {solvent blank }}}\right] \times 100 \%
$$

where $A_{\text {sample }}$ is the absorbance of the mixture of kiwifruit extract, $\alpha$-glucosidase solution, and PNPG solution $\mathrm{A}_{\text {blank }}$ is the absorbance of the mixture of kiwifruit extract, buffer, and $\alpha$-glucosidase solution; $\mathrm{A}_{\text {control }}$ is the absorbance of the mixture of buffer, $\alpha$-glucosidase solution, and PNPG solution; and $\mathrm{A}_{\text {solvent blank }}$ is the absorbance of buffer solution.

\subsection{Statistical Analysis}

All experiments were conducted in triplicate, and data were expressed in means \pm standard deviations. Statistical analysis was performed using SPSS 20.0 software (SPSS 20.0, IBM, Armonk, NY, USA), and the differences among mean values were tested by one-way ANOVA (SPSS 20.0, IBM, Armonk, NY, USA), taking a level of $p<0.05$ as significant to Duncan's multiple range test.

\section{Conclusions}

Significant differences were observed in the physicochemical properties and phenolic profiles of different kiwifruits, as well as in the antioxidant capacities and inhibitory effects on digestive enzymes. The total phenolic content of Actinidia chinensis cv. Hongshi, A. chinensis cv. Jinshi, and A. chinensis cv. Jinlong were $16.52 \pm 0.26 \mathrm{mg}$ GAE/g DW, $13.38 \pm 0.20 \mathrm{mg}$ GAE/g DW, and $11.02 \pm 0.05 \mathrm{mg}$ GAE/g DW, respectively, which were much higher than those of the other tested kiwifruits. According 
to HPLC analysis, procyanidin B1, procyanidin B2, (-)-epicatechin, chlorogenic acid, gallic acid, and quercetin-3-rhamnoside are the main phenolic compounds in kiwifruits. Furthermore, all the tested kiwifruits exerted remarkable antioxidant capacities and inhibitory effects on pancreatic lipase and $\alpha$-glucosidase. Phenolic compounds, such as chlorogenic acid, procyanidin B1, procyanidin B2, quercetin-3-rhamnoside, and quercetin-3-O-glucoside, could be the major contributors toward antioxidant capacities and enzyme inhibition effects of kiwifruits. Indeed, A. chinensis cv. Hongshi, Actinidia chinensis cv. Jinshi, and Actinidia chinensis cv. Jinlong exhibited much better antioxidant capacities and inhibitory effects on digestive enzymes (pancreatic lipase and $\alpha$-glucosidase) than those of the other tested kiwifruits. Particularly, A. polygama showed the highest inhibitory activity on $\alpha$-glucosidase. Therefore, Actinidia chinensis cv. Hongshi, Actinidia chinensis cv. Jinshi, and Actinidia chinensis cv. Jinlong, as well as A. polygama could be important dietary sources of natural antioxidants and natural inhibitors against pancreatic lipase and $\alpha$-glucosidase, which could be explored further as functional food ingredients for industrial applications.

Author Contributions: D.-T.W. and W.Q. conceived and designed the experiments; H.-Y.L. and Q.Y. performed the experiments; D.-T.W., W.Q., H.-Y.L., L.Z. and Q.Z. analyzed the data; Q.-H.H., Y.-L.Y., S.-X.L., D.-R.L. and J.-L.H. contributed reagents/materials/analysis tools; D.-T.W. and H.-Y.L. wrote the initial draft; D.-T.W. and W.Q. revised the manuscript.

Funding: This work was supported by the Scientific Research Foundation of Sichuan Agricultural University (grant number 03120321), and the Scientific Research Fund Project of Science \& Technology Department of Sichuan Province (grant numbers 2017NZ0039, 2018NZ0010, and 2018JY0149).

Conflicts of Interest: The authors declare that there are no conflicts of interest.

\section{References}

1. Du, G.; Li, M.; Ma, F.; Liang, D. Antioxidant capacity and the relationship with polyphenol and Vitamin C in Actinidia fruits. Food Chem. 2009, 113, 557-562. [CrossRef]

2. Zuo, L.L.; Wang, Z.Y.; Fan, Z.L.; Tian, S.Q.; Liu, J.R. Evaluation of antioxidant and antiproliferative properties of three Actinidia (Actinidia kolomikta, Actinidia arguta, Actinidia chinensis) extracts in vitro. Int. J. Mol. Sci. 2012, 13, 5506-5518. [CrossRef] [PubMed]

3. Nowicka, A.; Kucharska, A.Z.; Sokol-Letowska, A.; Fecka, I. Comparison of polyphenol content and antioxidant capacity of strawberry fruit from 90 cultivars of Fragaria $\times$ ananassa Duch. Food Chem. 2019, 270, 32-46. [CrossRef] [PubMed]

4. Boudaoud, H.; Debbache, N.; Berboucha, M.; Atmani, D.; Chaher, N.; Atmani, D. Flavonoids in Human Health: From Structure to Biological Activity. Curr. Nutr. Food Sci. 2009, 5, 225-237.

5. Ariza, M.T.; Reboredo-Rodriguez, P.; Cervantes, L.; Soria, C.; Martinez-Ferri, E.; Gonzalez-Barreiro, C.; Cancho-Grande, B.; Battino, M.; Simal-Gandara, J. Bioaccessibility and potential bioavailability of phenolic compounds from achenes as a new target for strawberry breeding programs. Food Chem. 2018, 248, 155-165. [CrossRef] [PubMed]

6. Hung, H.C.; Joshipura, K.J.; Jiang, R.; Hu, F.B.; Hunter, D.; Smithwarner, S.A.; Colditz, G.A.; Rosner, B.; Spiegelman, D.; Willett, W.C. Fruit and Vegetable Intake and Risk of Major Chronic Disease. J. Natl. Cancer Inst. 2004, 96, 1577-1584. [CrossRef] [PubMed]

7. D’Evoli, L.; Moscatello, S.; Lucarini, M.; Aguzzi, A.; Gabrielli, P.; Proietti, S.; Battistelli, A.; Famiani, F.; Böhm, V.; Lombardi-Boccia, G. Nutritional traits and antioxidant capacity of kiwifruit (Actinidia deliciosa Planch., cv. Hayward) grown in Italy. J. Food Compos. Anal. 2015, 37, 25-29. [CrossRef]

8. Podsedek, A.; Majewska, I.; Redzynia, M.; Sosnowska, D.; Koziolkiewicz, M. In vitro inhibitory effect on digestive enzymes and antioxidant potential of commonly consumed fruits. J. Agric. Food Chem. 2014, 62, 4610-4617. [CrossRef] [PubMed]

9. Tan, Y.; Chang, S.K.C.; Zhang, Y. Comparison of $\alpha$-amylase, $\alpha$-glucosidase and lipase inhibitory activity of the phenolic substances in two black legumes of different genera. Food Chem. 2017, 214, 259-268. [CrossRef] [PubMed] 
10. Zhang, B.; Deng, Z.; Ramdath, D.D.; Tang, Y.; Chen, P.X.; Liu, R.; Liu, Q.; Tsao, R. Phenolic profiles of 20 Canadian lentil cultivars and their contribution to antioxidant activity and inhibitory effects on $\alpha$-glucosidase and pancreatic lipase. Food Chem. 2015, 172, 862-872. [CrossRef] [PubMed]

11. Nishiyama, I. Fruits of the Actinidia Genus. Adv. Food Nutr. Res. 2007, 52, 293-324. [PubMed]

12. Latocha, P.; Jankowski, P.; Radzanowska, J. Genotypic difference in postharvest characteristics of hardy kiwifruit (Actinidia arguta and its hybrids), as a new commercial crop Part I. Sensory profiling and physicochemical differences. Food Res. Int. 2011, 44, 1936-1945. [CrossRef]

13. Pérez-Burillo, S.; Oliveras, M.J.; Quesada, J.; Rufián-Henares, J.A.; Pastoriza, S. Relationship between composition and bioactivity of persimmon and kiwifruit. Food Res. Int. 2018, 105, 461-472. [CrossRef] [PubMed]

14. Wojdylo, A.; Nowicka, P.; Oszmianski, J.; Golis, T. Phytochemical compounds and biological effects of Actinidia fruits. J. Funct. Food 2017, 30, 194-202. [CrossRef]

15. Ciacci, C.; Russo, I.; Bucci, C.; Iovino, P.; Pellegrini, L.; Giangrieco, I.; Tamburrini, M.; Ciardiello, M.A. The kiwi fruit peptide kissper displays anti-inflammatory and anti-oxidant effects in in-vitro and ex-vivo human intestinal models. Clin. Exp. Immunol. 2014, 175, 476-484. [CrossRef] [PubMed]

16. Garcia, C.V.; Quek, S.Y.; Stevenson, R.J.; Winz, R.A. Kiwifruit flavour: A review. Trends Food Sci. Technol. 2012, 24, 82-91. [CrossRef]

17. Ma, T.; Sun, X.; Zhao, J.; You, Y.; Lei, Y.; Gao, G.; Zhan, J. Nutrient compositions and antioxidant capacity of kiwifruit (Actinidia) and their relationship with flesh color and commercial value. Food Chem. 2017, 218, 294-304. [CrossRef] [PubMed]

18. White, A.; Nihal de Silva, H.; Requejo-Tapia, C.; Roger Harker, F. Evaluation of softening characteristics of fruit from 14 species of Actinidia. Postharvest Biol. Technol. 2005, 35, 143-151. [CrossRef]

19. Burdon, J.; Lallu, N.; Pidakala, P.; Barnett, A. Soluble solids accumulation and postharvest performance of 'Hayward' kiwifruit. Postharvest Biol. Technol. 2013, 80, 1-8. [CrossRef]

20. Ercisli, S.; Orhan, E. Chemical composition of white (Morus alba), red (Morus rubra) and black (Morus nigra) mulberry fruits. Food Chem. 2007, 103, 1380-1384. [CrossRef]

21. Krupa, T.; Latocha, P.; Liwińska, A. Changes of physicochemical quality, phenolics and vitamin $C$ content in hardy kiwifruit (Actinidia arguta and its hybrid) during storage. Sci. Hortic. 2011, 130, 410-417. [CrossRef]

22. Lim, Y.J.; Oh, C.S.; Park, Y.D.; Eom, S.H.; Kim, D.O.; Kim, U.J.; Cho, Y.S. Physiological components of kiwifruits with in vitro antioxidant and acetylcholinesterase inhibitory activities. Food Sci. Biotechnol. 2014, 23, 943-949. [CrossRef]

23. Park, Y.S.; Namiesnik, J.; Vearasilp, K.; Leontowicz, H.; Leontowicz, M.; Barasch, D.; Nemirovski, A.; Trakhtenberg, S.; Gorinstein, S. Bioactive compounds and the antioxidant capacity in new kiwi fruit cultivars. Food Chem. 2014, 165, 354-361. [CrossRef] [PubMed]

24. Leontowicz, H.; Leontowicz, M.; Latocha, P.; Jesion, I.; Park, Y.S.; Katrich, E.; Barasch, D.; Nemirovski, A.; Gorinstein, S. Bioactivity and nutritional properties of hardy kiwi fruit Actinidia arguta in comparison with Actinidia deliciosa 'Hayward' and Actinidia eriantha 'Bidan'. Food Chem. 2016, 196, 281-291. [CrossRef] [PubMed]

25. Guo, J.; Yuan, Y.; Dou, P.; Yue, T. Multivariate statistical analysis of the polyphenolic constituents in kiwifruit juices to trace fruit varieties and geographical origins. Food Chem. 2017, 232, 552-559. [CrossRef] [PubMed]

26. Kim, J.G.; Beppu, K.; Kataoka, I. Varietal differences in phenolic content and astringency in skin and flesh of hardy kiwifruit resources in Japan. Sci. Hortic. 2009, 120, 551-554. [CrossRef]

27. Dawes, H.M.; Keene, J.B. Phenolic Composition of Kiwifruit Juice. J. Agric. Food Chem. 1999, 47, $2398-2403$. [CrossRef] [PubMed]

28. Park, Y.S.; Leontowicz, H.; Leontowicz, M.; Namiesnik, J.; Suhaj, M.; Cvikrová, M.; Martincová, O.; Weisz, M.; Gorinstein, S. Comparison of the contents of bioactive compounds and the level of antioxidant activity in different kiwifruit cultivars. J. Food Compos. Anal. 2011, 24, 963-970. [CrossRef]

29. Juárez-Trujillo, N.; Monribot-Villanueva, J.L.; Alvarado-Olivarez, M.; Luna-Solano, G.; Guerrero-Analco, J.A.; Jiménez-Fernández, M. Phenolic profile and antioxidative properties of pulp and seeds of Randia monantha Benth. Ind. Crop. Prod. 2018, 124, 53-58. [CrossRef]

30. Moreno, D.A.; Ilic, N.; Poulev, A.; Brasaemle, D.L.; Fried, S.K.; Raskin, I. Inhibitory effects of grape seed extract on lipases. Nutrition 2003, 19, 876-879. [CrossRef] 
31. McDougall, G.J.; Kulkarni, N.N.; Stewart, D. Berry polyphenols inhibit pancreatic lipase activity in vitro. Food Chem. 2009, 115, 193-199. [CrossRef]

32. Sakulnarmrat, K.; Konczak, I. Composition of native Australian herbs polyphenolic-rich fractions and in vitro inhibitory activities against key enzymes relevant to metabolic syndrome. Food Chem. 2012, 134, 1011-1019. [CrossRef] [PubMed]

33. Sergent, T.; Vanderstraeten, J.; Winand, J.; Beguin, P.; Schneider, Y.J. Phenolic compounds and plant extracts as potential natural anti-obesity substances. Food Chem. 2012, 135, 68-73. [CrossRef]

34. Nowicka, P.; Wojdyło, A.; Samoticha, J. Evaluation of phytochemicals, antioxidant capacity, and antidiabetic activity of novel smoothies from selected Prunus fruits. J. Funct. Food. 2016, 25, 397-407. [CrossRef]

35. Ishikawa, A.; Yamashita, H.; Hiemori, M.; Inagaki, E.; Kimoto, M.; Okamoto, M.; Tsuji, H.; Memon, A.N.; Mohammadi, A.; Natori, Y. Characterization of inhibitors of postprandial hyperglycemia from the leaves of Nerium indicum. J. Nutr. Sci. Vitaminol. 2007, 53, 166-173. [CrossRef] [PubMed]

36. Wang, B.N.; Liu, H.F.; Zheng, J.B.; Fan, M.T.; Cao, W. Distribution of phenolic acids in different tissues of jujube and their antioxidant activity. J. Agric. Food Chem. 2011, 59, 1288-1292. [CrossRef] [PubMed]

37. Lin, S.; Guo, H.; Gong, J.D.B.; Lu, M.; Lu, M.Y.; Wang, L.; Zhang, Q.; Qin, W.; Wu, D.T. Phenolic profiles, $\beta$-glucan contents, and antioxidant capacities of colored Qingke (Tibetan hulless barley) cultivars. J. Cereal Sci. 2018, 81, 69-75. [CrossRef]

38. Almeida, D.; Pinto, D.; Santos, J.; Vinha, A.F.; Palmeira, J.; Ferreira, H.N.; Rodrigues, F.; Oliveira, M. Hardy kiwifruit leaves (Actinidia arguta): An extraordinary source of value-added compounds for food industry. Food Chem. 2018, 259, 113-121. [CrossRef] [PubMed]

39. Yang, M.; Shen, Q.; Li, L.Q.; Huang, Y.Q.; Cheung, H.Y. Phytochemical profiles, antioxidant activities of functional herb Abrus cantoniensis and Abrus mollis. Food Chem. 2015, 177, 304-312. [CrossRef] [PubMed]

Sample Availability: Samples of raw materials of different kiwifruits are available from the authors.

(C) 2018 by the authors. Licensee MDPI, Basel, Switzerland. This article is an open access article distributed under the terms and conditions of the Creative Commons Attribution (CC BY) license (http:/ / creativecommons.org/licenses/by/4.0/). 